\title{
Age of Individuals Undergoing Cleft Lip and Cleft Palate Surgeries in Nepal
}

\author{
Shankar Man Rai, ${ }^{1}$ Kiran Nakarmi, ${ }^{1}$ Surendra Basnet, ${ }^{1}$ Pramila Shakya, ${ }^{1}$ Krishna Nagarkoti, ${ }^{1}$ Mangal \\ Ghartimagar,' Bishal Karki, ${ }^{\text {S Suzita Hirachan' }}$ \\ 'Department of Burns, Plastic and Reconstructive Surgery, Kathmandu Model Hospital, Exhibition Road, Kathmandu, Nepal.
}

\section{ABSTRACT}

Introduction: Timely repair of cleft lip and palate maximises the benefits of surgery. Developing countries have large number of adults with unrepaired clefts. The impact of a cleft program can be determined by observing the trends of lower age at surgery. Public Health Concern Trust, Nepal has been providing a comprehensive nationwide cleft service since 1999. This study was conducted to see any change in the age at surgery.

Methods: A retrospective cross sectional study was conducted to analyse the data of all the individuals' age at primary cleft surgery from July 1999 to June 2010. Mean and median age of individuals as well as the proportion of individuals operated on the right age in different years were calculated and compared.

Results: The median age for cleft lip surgery decreased from 100 to 24 months. Similarly the median age for cleft palate surgery decreased from 70 to 28 months. Proportion of surgeries carried out in the recommended age also increased. A change in the policy of the program reaching out to more remote areas and removing the age barrier for surgery resulted in older adults receiving surgery and increased median age especially for cleft palate repairs.

Conclusions: A nationwide cleft program for a decade had a small impact on age at surgery. There are still many individuals who are missing the ideal age for surgery. The program needs to reach more remote areas. This information will be useful for governmental as well as non-governmental organizations working in the area of clefts.

Keywords: age; cleft lip; cleft palate; Nepal.

\section{INTRODUCTION}

American Cleft Palate Association (ACPA) has guidelines that cleft lip should be repaired within the first six months and that cleft palate should be repaired within 18 months of life. ${ }^{1}$ Age at the time of cleft surgery is important for the outcome of surgery. ${ }^{2,3}$

ReSurge International used to send cleft surgical teams to Nepal since early 1980 s. In collaboration with the
Smile Train, it started Resurge International Surgical Outreach Program (RISOP) under Public Health Concern Trust-Nepal in 1999 to empower a local cleft surgical team to provide service on regular basis which has already been reported. ${ }^{4}$ RISOP has been providing a multidisciplinary service year round on regular basis in

Correspondence: Dr. Shankar Man Rai, Department of Burns, Plastic and Reconstructive Surgery, Kathmandu Model Hospital, Kathmandu, Nepal. Email: shankarrai1956@gmail.com, Phone: +9779841295062 
seven different centres across Nepal.

This study analysed the impact of the program on the back-log of burden of cleft by studying the trend of age at the time of cleft surgery which is important for future planning.

\section{METHODS}

A retrospective cross section study was conducted with the data of individuals who had undergone primary cleft lip and/or cleft palate surgery from July 1999 to June 2010. Data on the age of individuals operated under Resurge International Outreach Program (RISOP) in a total of seven centres (Kathmandu, Biratnagar, Birgunj, Butwal, Chitwan, Pokhara and Nepalgunj) were analysed using Microsoft Excel 2003 Worksheet. All the individuals who had undergone surgeries of the primary repair of cleft lip and /or cleft palate were included while the individuals who had undergone secondary cleft surgeries e.g. revision, velopharyngeal procedure, cleft rhinoplasty, alveolar bone grafts were excluded.

The mean and median age of the patients at the time of cleft lip and cleft palate repairs were calculated for each year. Similarly the proportion of patients who had undergone cleft lip repair before the age of six months which is an ideal age for cleft lip surgery were calculated. For patients who had undergone palate repair, the proportion was calculated for patients of age 18 months or less and older. The findings from each year were compared to see if there was any changing trend in the age at cleft surgery. Descriptive statistical analysis was done using ' $Z$ ' test and ' $t$ ' test to see if the changes were statistically significant with a confidence interval of $95 \%$.

\section{RESULTS}

There were 8804 individuals who had undergone primary cleft surgery during the study period. The distribution of the number of cleft lip and cleft palate surgeries for each year is shown in (Table 1).

The mean age of the individuals at the time of the lip repair gradually decreased from 139 months in 19992000 to a statistically significant lower figure of 48 months in 2005-2006 ( $\leq \leq 0.05)$ but later it started increasing slowly to a maximum of 87 in 2008-2009 which is still significantly lower than the value in the beginning of the program $(P \leq 0.05)$. Similarly the mean age at the time of palate repair also decreased gradually from 85 months in the year 2000-2001 to a minimum of 51 months in 2005-2006 (P $\leq 0.05)$ but later it increased to a maximum of 107 months in 2008-2009 which is higher than at the beginning of the program
(Table 2).

\begin{tabular}{|c|c|c|}
\hline Year & $\begin{array}{l}\text { Lip Repair } \\
(n=7334)\end{array}$ & $\begin{array}{l}\text { Palate Repair } \\
(n=1470)\end{array}$ \\
\hline 1999-2000 & 499 & 109 \\
\hline 2000-2001 & 1058 & 194 \\
\hline 2001-2002 & 842 & 189 \\
\hline $2002-2003$ & 513 & 145 \\
\hline 2003-2004 & 495 & 147 \\
\hline 2004-2005 & 471 & 126 \\
\hline 2005-2006 & 480 & 97 \\
\hline 2006-2007 & 667 & 56 \\
\hline 2007-2008 & 813 & 127 \\
\hline 2008-2009 & 782 & 143 \\
\hline $2009-2010$ & 714 & 137 \\
\hline
\end{tabular}

Table 2. Yearly distribution of mean and median age at the time of the cleft lip and cleft palate repair $(n=8804)$.

\begin{tabular}{|ccccc|}
\hline Year & \multicolumn{2}{c|}{$\begin{array}{c}\text { Age in months } \\
\text { at lip repair }\end{array}$} & \multicolumn{2}{c|}{$\begin{array}{c}\text { Age in months at } \\
\text { palate repair }\end{array}$} \\
& Mean & Median & Mean & Median \\
$1999-2000$ & 139 & 100 & 83 & 65 \\
$2000-2001$ & 131 & 96 & 85 & 70 \\
$2001-2002$ & 115 & 74 & 70 & 58 \\
$2002-2003$ & 66 & 35 & 66 & 43 \\
$2003-2004$ & 67 & 37 & 66 & 35 \\
$2004-2005$ & 60 & 32 & 61 & 30 \\
$2005-2006$ & 48 & 24 & 51 & 28 \\
$2006-2007$ & 63 & 35 & 87 & 73 \\
$2007-2008$ & 77 & 40 & 103 & 87 \\
$2008-2009$ & 87 & 45 & 107 & 97 \\
$2009-2010$ & 85 & 39 & 103 & 100 \\
\hline & & & & \\
\hline
\end{tabular}

Presentation of individuals at an older age skews the mean age to higher levels. For this reason, median age in months was also calculated for each year for both cleft lip and cleft palate repairs. Median age at operation was lower than the mean age in each year for both cleft lip and cleft palate repairs. Median age for the lip repair was 100 months (8.3 years) when the program started and it came down to the lowest level of 24 months (2 years) in the year 2005-2006 $(\mathrm{P} \leq 0.05)$ but later it went up to 45 months (3.7 years) 
in the year 2008-2009. Similarly, the median age at the time of cleft palate repair was highest (70 months) in the year 2000-2001 which came down to the 28 months $(\mathrm{P} \leq 0.05)$ but later it went up to 100 months (8.3 years) in the year 2009-2010.

The proportion of individuals who had undergone cleft lip repair at or before the age of six months also increased gradually from a minimum of $40(3.8 \%)$ in the year $2000-2001$ to a maximum of $78(16.2 \%)$ in the year 2005-2006 ( $\leq \leq 0.05)$ which again decreased to a minimum of $71(8.7 \%)$ in the year 2007-2008. It again showed an increasing trend to reach $89(12.5 \%)$ in 2009-2010 (Table 3).

Similarly, the proportions of individuals who had undergone cleft lip repair at or beyond the age of 20 years also has decreased from $84(17.4 \%)$ in the year $1999-2000$ to a minimum of $7(1.5 \%)$ in $2005-2006$ $(\mathrm{P} \leq 0.05)$ but after this year, the proportion started increasing slowly to $68(8.7 \%)$ in $2009-2010$ ( $p \leq 0.05)$.

The proportion of individuals who had undergone cleft palate repair at or before the age of 18 months also increased gradually from $4(3.7 \%)$ in $1999-2000$ to 28 $(28.9 \%)$ in $2005-2006$ ( $\mathrm{p} \leq 0.05)$ but the proportion decreased after that year to $3(5.3 \%)$ in the year 2006 2007.

The proportion of individuals who were 20 years or older at the time of palate repair also decreased from 4 $(2.7 \%)$ in the year $2002-2003$ to $0 \%$ in the year 2004 but later increased to $6(4.2 \%)$ in the year 2008-2009 (Table 4).

\begin{tabular}{|c|c|c|c|c|c|c|c|c|}
\hline \multirow[t]{2}{*}{ YEAR } & \multicolumn{2}{|c|}{$\begin{array}{l}\text { Individuals } \\
\text { Upto } 6 \text { months age }\end{array}$} & \multicolumn{2}{|c|}{$\begin{array}{l}\text { Individuals } \\
>6-60 \text { months }\end{array}$} & \multicolumn{2}{|c|}{$\begin{array}{l}\text { Individuals } \\
>60-240 \text { months }\end{array}$} & \multicolumn{2}{|c|}{$\begin{array}{l}\text { Individuals } \\
>240 \text { months }\end{array}$} \\
\hline & $\%$ & (n) & $\%$ & (n) & $\%$ & (n) & $\%$ & (n) \\
\hline 1999-2000 & 4 & (20) & 31.1 & (155) & 47.5 & (237) & 17.4 & (87) \\
\hline $2000-2001$ & 3.8 & $(40)$ & 28.8 & (305) & 51.4 & (544) & 16 & (169) \\
\hline 2001-2002 & 6.8 & (57) & 36.7 & (309) & 42.5 & (358) & 14.0 & (118) \\
\hline $2002-2003$ & 9.9 & $(51)$ & 54.8 & $(281)$ & 33.7 & (173) & 1.6 & (8) \\
\hline 2003-2004 & 18.1 & (95) & 44.6 & (234) & 35.8 & (188) & 1.5 & (8) \\
\hline 2004-2005 & 13.6 & (64) & 51.2 & $(241)$ & 33.7 & (159) & 1.5 & (7) \\
\hline 2005-2006 & 16.2 & $(78)$ & 55.6 & (267) & 26.7 & $(128)$ & 1.5 & (7) \\
\hline 2006-2007 & 12.6 & (84) & 56.4 & (376) & 28.3 & (189) & 2.7 & (18) \\
\hline 2007-2008 & 8.7 & (71) & 49.5 & (402) & 35.8 & (291) & 6 & (49) \\
\hline 2008-2009 & 10.2 & $(80)$ & 47.5 & (371) & 33.6 & (263) & 8.7 & (68) \\
\hline 2009-2010 & 12.5 & (89) & 48.3 & (345) & 31.2 & (223) & 8 & (57) \\
\hline
\end{tabular}

\begin{tabular}{|c|c|c|c|c|c|c|c|c|c|c|}
\hline \multirow[t]{3}{*}{ YEAR } & \multirow{2}{*}{\multicolumn{2}{|c|}{$\begin{array}{c}\text { Individuals aged } \\
18 \text { months or } \\
\text { younger }\end{array}$}} & \multicolumn{2}{|c|}{$\begin{array}{l}>18 \text { months to } \\
36 \text { months }\end{array}$} & \multicolumn{2}{|c|}{$\begin{array}{c}>3 \text { years to } 10 \\
\text { years }\end{array}$} & \multicolumn{2}{|c|}{$\begin{array}{c}>10 \text { years to } 20 \\
\text { years }\end{array}$} & \multicolumn{2}{|c|}{$>20$ years } \\
\hline & & & \multirow{2}{*}{$\%$} & \multirow{2}{*}{ (n) } & \multirow{2}{*}{$\%$} & \multirow{2}{*}{$(n)$} & \multirow{2}{*}{$\%$} & \multirow{2}{*}{ (n) } & \multirow{2}{*}{$\%$} & \multirow[t]{2}{*}{ (n) } \\
\hline & & & & & & & & & & \\
\hline 1999-2000 & 3.7 & (4) & 23.9 & (26) & 41.3 & (45) & 29.3 & (32) & 1.8 & (2) \\
\hline $2000-2001$ & 8.2 & (16) & 16.0 & (31) & 53.1 & (103) & 20.6 & (40) & 2.1 & (4) \\
\hline 2001-2002 & 10.6 & (20) & 22.2 & (42) & 50.3 & (95) & 15.9 & (30) & 1 & (2) \\
\hline 2002-2003 & 13.8 & (20) & 26.9 & (39) & 42.8 & (62) & 13.8 & (20) & 2.7 & (4) \\
\hline 2003-2004 & 19 & (28) & 32.7 & (48) & 28.6 & (42) & 18.4 & (27) & 1.3 & (2) \\
\hline 2004-2005 & 24.6 & (31) & 30.2 & (38) & 28.6 & (36) & 16.6 & (21) & & \\
\hline 2005-2006 & 28.9 & (28) & 28.9 & (28) & 28.9 & (28) & 13.3 & (13) & & \\
\hline 2006-2007 & 5.3 & (3) & 25 & (14) & 39.3 & (22) & 26.8 & (15) & 3.6 & (2) \\
\hline 2007-2008 & 6.3 & (8) & 8.7 & (11) & 47.2 & (60) & 34.6 & (44) & 3.2 & (4) \\
\hline 2008-2009 & 6.3 & (9) & 12.6 & (18) & 42.6 & (61) & 34.3 & (49) & 4.2 & (6) \\
\hline 2009-2010 & 8 & (11) & 19. & (26) & 32.8 & (45) & 36.5 & (50) & 3.7 & (5) \\
\hline
\end{tabular}




\section{DISCUSSION}

The timely repair of cleft deformities is important for both medical and psychological reasons. It also has an immense economic impact on public health by reducing the surgical burden of disease with implication on health policy and funding and resource allocation. ${ }^{5}$ Several studies have shown the benefits of early cleft palate surgery on speech outcomes as well as on the incidence of velopharyngeal incompetence (VPI) requiring secondary velopharyngeal procedures. ${ }^{6,7}$ Studies have shown that the individuals with cleft deformity in the developing countries present for corrective surgery later than the recommended age..$^{8,9}$

The Smile Train is the organization which has provided the largest number of cleft surgical service in the whole world. In India alone, with a population over a billion, it has been able to provide over 160000 cleft surgeries by the end of 2011. In spite of that many surgeries in India, most children are not able to undergo surgery at the recommended age. In G S Memorial Hospital, India where probably the largest number of cleft surgeries is performed in the world every year $(2780$ in 2006, 3583 in 2007, 3717 in 2008, over 4000 in 2009), the average age at surgery was 6.6 years in the year 2004, 7.6 years in 2007 and 6.2 years in 2009 . Another Indian study reported that only $43.6 \%$ of clefts were operated before the age of 2 years. 10 Even in a developed country like the United States, not all the children are operated in the ideal age as recommended by ACPA. In one study from North Carolina, only $78 \%$ of children had surgery within 18 months of age. ${ }^{3}$

To bring a significant change in the age at cleft surgery in any population, a significant number of cleft surgeries will have to be performed to clear the back log and the cleft surgical services will have to be continued with easy access to all the children with cleft deformities so that the remaining cleft surgeries will be performed in an early age. This needs a long term commitment on the part of the service provider as well as education and awareness on the part of the community to access the cleft surgical service in the right age.

With the prevalence rate of $1.64 / 1000$ for cleft deformities at birth, the calculated maximum burden of cleft in Nepal is around 42640. ${ }^{12}$ With 8804 individuals operated under a single cleft program in the country where there are multiple organizations performing cleft surgeries, the awareness in the community about the availability of cleft surgical service free of cost seems to have increased now. Availability of the cleft surgical service is not a problem anymore in several peripheral towns of Nepal. Thus, the most important step in bringing the change in the scenario of age at the time of cleft surgery is the clearance of the back-log of adult cleft cases in the remote areas as well as continuation of service nationwide.

Before the year 2006, The Smile Train covered cleft surgeries only up to the age of 20 years and below. When the age limit was lifted it increased the access to cleft surgical service to older individuals. In the same year of 2006, the RISOP decided to send community coordinators to more remote areas of the country to recruit new cleft cases. This improved the access of the service to older individuals in the remote areas who had been marginalized in the past. Both of these changes in the year 2006 increased the mean and median age for both cleft lip and cleft palate surgeries which is very well reflected in the present study. The change in the Smile Train policy in 2006 was also reflected the Indian data. ${ }^{10}$

The present study showed that there are many individuals with cleft deformities in Nepal who have not been able to access the service in the recommended age. The need for the cleft program to reach more remote areas with many adults with cleft deformities is evident. Continued monitoring of age at the time of primary cleft surgery will be necessary to see the future trends.

\section{CONCLUSIONS}

A cleft program operational nationwide for a decade has had a small impact on age at cleft surgery. The trend of lower age at the time of cleft surgery was more obvious in the case of cleft lip than in cleft palate. There are still many individuals who are missing the ideal age for cleft surgery in Nepal. The program needs to reach more remote areas. Monitoring of age at the time of cleft surgery needs to be continued to see the trend. This information will be useful to plan the future cleft programs. Governmental as well as non-governmental organizations working in the field of cleft should focus on reaching the remote areas to clear the adult back-log of cases.

\section{ACKNOWLEDGEMENT}

Authors want to thank Resurge International for providing the support to phect-NEPAL to run the RISOP. We also thank our coordinators who take the service to remote areas and for collection of data. 


\section{REFERENCES}

1. American Cleft Palate-Craniofacial Association. Parameters for evaluation and treatment of patients with cleft lip/palate or other craniofacial anomalies. Cleft Palate Craniofac J. 1993 Mar;30(suppl):S1-16.

2. Dorf DS, Curtin JW. Early cleft palate repair and speech outcome. Plast Reconstr Surg. 1982 Jul;70(1):74-81.

3. Cassell $\mathrm{CH}$, Daniels J, Meyer R. Timeliness of primary cleft lip/palate surgery. Cleft Palate Craniofac J. 2009 Nov;46(6):588-97.

4. Zbar RI, Rai SM, Dingman DL. Establishing cleft malformation surgery in developing nations: a model for the new millennium. Plast Reconstr Surg. 2000 Sept;106(4):886-9.

5. Corlew DS. Estimation of impact of surgical disease through economic modeling of cleft lip and palate case. World J Surg. 2010 Mar;34(3):391-6.

6. Haapanen ML, Rantala SL. Correlation between the age at repair and speech outcome in patients with isolated cleft palate. Scand J Plast and Recons Surg and Hand Surg. 1992; 26(1):71-8.
7. Dorf DS, Curtin JW. Early cleft palate repair and speech outcome: a ten-year experience. In: Bardach J and Morris HL, editors. Multidisciplinary management of cleft lip and palate. Philadelphia; Saunders: 1990. p 341-8.

8. Aziz SR, Rhee ST, Redai I. Cleft Surgery in Rural Bangladesh: reflections and experiences. J Oral Maxillofac Surg. 2009 Aug;67(8):1581-8.

9. Singh SK. Smile Train: the ascendancy of cleft care in India. Indian J Plast Surg. 2009; 42(Suppl): S193-8.

10. Agrawal K. Clinical and demographic profile of cleft lip and cleft palate in Sub-Himalayan India: a hospital based study. Indian J Plast Surg. 2012 Jan- Apr;45(1):120-1.

11. Singh VP, Sagtani R, Sagtani A. Prevalence of cleft lip and cleft palate in a tertiary hospital in eastern Nepal. Mymensing Med J. 2012 Jan;21(1):151-4. 